\title{
Supporting medical students with learning disabilities in Asian medical schools
}

This article was published in the following Dove Press journal:

Advances in Medical Education and Practice

6 October 2010

Number of times this article has been viewed

\author{
Md. Anwarul Azim Majumder \\ Sayeeda Rahman ${ }^{2}$ \\ Urban JA D'Souza ${ }^{3}$ \\ Gad Elbeheri ${ }^{4}$ \\ Khalid Bin Abdulrahman ${ }^{5}$ \\ M Muzaherul Huq 6 \\ 1,2Department of Clinical Sciences, \\ School of Life Sciences, University of \\ Bradford, West Yorkshire, Bradford, \\ UK; ${ }^{3}$ School of Medicine, University \\ Malaysia Sabah, Kota Kinabalu, Sabah, \\ Malaysia; ${ }^{4}$ Centre for Child Evaluation \\ and Teaching, Kuwait; ${ }^{5}$ College of \\ Medicine, Al-Imam University, Riyadh, \\ Saudi Arabia; ${ }^{6}$ Centre for Medical \\ Education (CME), Mohakhali, Dhaka, \\ Bangladesh
}

\begin{abstract}
Learning disabilities (LDs) represent the largest group of disabilities in higher education (HE) institutes, including medical schools, and the numbers are continuing to rise. The worrying concern is that two-thirds to half of these students with LDs remain undiagnosed when they start their undergraduate education and may even graduate without having their disabilities diagnosed. These students struggle with their academic abilities, receive poor grades and, as a result, develop lower perceptions of their intellectual abilities than do those students without LDs. All these ultimately hamper their professional practice, employment, and career progression. Appropriate and adequate educational policies, provisions, and practices help students to progress satisfactorily. In Asian countries, public and professional awareness about LDs is low, supportive provisions are limited, legislations are inadequate, data are scarce, and equal-opportunity/widening-participation policies are not implemented effectively in the HE sector. This article discusses the issues related to LDs in medical education and draws policy, provision, and practice implications to identify, assess, and support students with LDs in medical schools, particularly in an Asian context.
\end{abstract}

Keywords: medical education, learning disabilities, dyslexia, Asia

\section{Introduction}

Widening-participation initiatives in many countries have opened doors for higher education (HE) to people from wider background and to diverse "nontraditional" groups (eg, those from low socioeconomic backgrounds, indigenous population, ethnic minorities, and those having disabilities). ${ }^{1-4}$ Increasing numbers of students with disabilities are now attending HE institutes, including medical schools, ${ }^{4-8}$ and legislation has ensured that students with disabilities are granted equal access to all aspects of education. ${ }^{1,2,5,6}$ The fastest growing category of disability in HE is that of learning disabilities (LDs). ${ }^{6-8}$ The concern is that two-thirds to half of students with LDs remain undiagnosed when they start their undergraduate education, ${ }^{8,9}$ and students may even graduate without having their disabilities diagnosed. ${ }^{9}$ Without support provisions in the HE, LDs may have deleterious consequences on students' progression, completion, and success ${ }^{10}$ and ultimately may hamper the professional practice, employment, and career progression in future..$^{5,11-13}$ Appropriate and adequate educational support helps students to progress satisfactorily. ${ }^{5,9,10}$ Although more students with LDs are enrolling in HE, their learning needs are not well understood and LDs are still considered as a "hidden, ignored, and unwelcome" agenda. ${ }^{14}$ In recent years, although much attention has been given to the needs of students with LDs in primary and secondary schools in Asian countries ${ }^{15-17}$ the needs and experiences of HE students with LDs have received 
less attention. This article will discuss the issues related to LDs in medical education and draw policy, provision, and practice implications to identify, assess, and support students with LDs in medical schools, particularly in the Asian context. To gather relevant information, the authors searched the electronic databases (eg, Medline/PubMed); contacted various organizations (eg, World Health Organization [WHO] and regional offices, dyslexic associations of different countries, and medical schools), medical educators, and psychiatrists; and referred to different journals, books, documents, and reports.

\section{Learning disabilities}

People with LDs experience difficulties in various stages of learning (eg, recording, interpreting, storing, and reproducing information), which may affect acquisition, organization, retention, understanding, or use of verbal or nonverbal information. ${ }^{18}$ McLean et al ${ }^{19}$ outlined "indicators of learning difficulties" (Table 1). Students with LDs may experience some or all of these difficulties in their university life. LDs are divided into four main types: dyslexia, dysgraphia, dyscalculia, and dyspraxia (Table 2). Dyslexia is the commonest cause of LDs in children and young people in schools, colleges, and universities.

\section{Prevalence of LDs}

"Dyslexia is less common in Asia than the US, but it's still a significant and largely unnoticed problem". ${ }^{23}$

LDs affect $10 \%-15 \%$ of the world's population, and it is estimated that $8 \%$ experience some degree of dyslexia, with $2 \%-4 \%$ being seriously affected. ${ }^{24}$ Dyspraxia and dyscalculia affect up to $5 \%$ and $3 \%-4 \%$ of the population, respectively. ${ }^{21}$ The incidence of dyslexia is $2 \%-15 \%$ in the United Kingdom, ${ }^{25} 15 \%-20 \%$ in the United States, ${ }^{26} 10 \%$ in Hungary, ${ }^{27} 5 \%$ in Saudi Arabia, ${ }^{28} 6.3 \%$ in Kuwait, ${ }^{17}$ and 10\% in Hong Kong. ${ }^{29}$ Approximately $6 \%-10 \%$ of school-aged

Table I Indicators of learning difficulties ${ }^{19}$

\begin{tabular}{ll}
\hline - Concentrating & - Following instructions or procedures \\
- Organizing time & - Understanding academic texts \\
- Reading, writing, or spelling & - Following social cues \\
- Calculating numerical & - Participating in group discussions \\
problems & - Demonstrating their ability in \\
- Completing tasks & assessments \\
- Following lectures & - Achieving grades that reflect their true \\
& abilities \\
\hline
\end{tabular}

Table 2 Learning disabilities: common definitions

Learning disabilities ${ }^{20}$-a heterogeneous group of disorders manifested by significant difficulties in the acquisition and use of listening, speaking, reading, writing, reasoning, or mathematical abilities, or of social skills.

Dyslexia"1 - literally means "difficulty with words" and often affects reading, writing, and spelling. It is a mix of both difficulties and strengths and varies from person to person.

Dyscalculia ${ }^{21}$-Dyscalculia is like dyslexia but affects numbers rather than words. People with dyscalculia experience difficulty with the basic aspects of numbers and arithmetic.

Dysgraphia $^{22}$ - a writing disability in which a person finds it hard to form letters or write within a defined space.

Dyspraxia ${ }^{21}$-impacts on fine motor skills, coordination, balance, and organization; a person with dyspraxia may be known as "particularly clumsy".

Auditory and visual processing disabilities ${ }^{22}$ — sensory disabilities in which a person has difficulty in understanding language, despite normal hearing and vision.

population in the United States have LDs, and nearly $40 \%$ of children enrolled in the nation's special education classes suffer from LDs. ${ }^{30}$ The prevalence of LDs, including dyslexia, among primary school pupils in selected Asian countries is shown in Table 3.

\section{LDs in $\mathrm{HE}$}

LDs represent the largest group of disabilities in HE, and statistics demonstrate yearly increases in students graduating with LDs, including dyslexia. ${ }^{4-8}$ In the United States, LDs constitute about a quarter of all disabilities reported in HE institutes. ${ }^{31}$ In the United Kingdom, Universities and Colleges Admissions Service (UCAS) data showed a gradual increase of students with LDs (both applicants and accepted) in HE institutes since 2004. ${ }^{7}$ Dyslexia constitutes the largest single disability category in HE. ${ }^{4,32}$ The incidence of dyslexia in traditional universities, new universities, and further education colleges in the United Kingdom is $0.95 \%$, $1.31 \%$, and $1.54 \%$, respectively ${ }^{33}$ and $0.16 \%$ in HE institutes in Greece. ${ }^{34}$

Table 3 LDs including dyslexia in primary school pupils in Asian countries $^{15}$

\begin{tabular}{ll}
\hline Country & Prevalence \\
\hline China & $4 \%-8 \%$ \\
India & $10 \%$ \\
Iran & $5.5 \%$ \\
Japan & $3 \%-4 \%$ \\
Malaysia & $7 \%$ \\
Singapore & $3 \%-5 \%$ \\
Taiwan & $7.5 \%$ \\
\hline
\end{tabular}




\section{LDs in medical schools}

Students with all types of disabilities account for $0.2 \%$ of medical school graduates in the United States. ${ }^{35,36}$ In the United Kingdom, 3\% of students in medicine and dentistry declared a disability in 2004/2005. ${ }^{37}$ The number of medical students with LDs is about $3 \%$ and $1.5 \%$ in the United States $^{8}$ and United Kingdom, ${ }^{7}$ respectively. Table 4 shows the applicant and accepted-applicant disability data in all medical schools in the United Kingdom from 2003 to 2007. ${ }^{7}$ The data indicate a gradual increase in the number of both applicant and accepted applicant disability data in UK medical schools. Moreover, LD applicants (accepted) as a percentage of total applicants with disability (accepted) have also increased during this period by about $13.4 \%$. In addition to medical schools, a significant number of students with LDs are also attending nursing ${ }^{32}$ dental,,${ }^{38,39}$ and other health professional institutes $^{40}$ (Table 5).

\section{Issues and approaches in LDs: implications for medical schools in Asia}

In recent years, innovation and experimentation in medical education in Asia ignited reorientation of medical curricula to provide need-based training for "tomorrow's doctors". ${ }^{44}$ However, these approaches failed substantially to influence educational policy and medical practices in comparison with those in developed countries. ${ }^{45}$

Reorientation of medical education is a dynamic process current practicing trends should be replaced with, or complemented by, innovative strategies and emerging trends, and

Table 4 Applicant and accepted applicant disability data in the UK medical schools (2003-2007)

\begin{tabular}{llllll}
\hline & $\mathbf{2 0 0 3}$ & $\mathbf{2 0 0 4}$ & $\mathbf{2 0 0 5}$ & $\mathbf{2 0 0 6}$ & $\mathbf{2 0 0 7}$ \\
\hline Total applicants & 14,833 & 17,826 & 19,360 & 18,949 & 18,597 \\
Total acceptances & 7,667 & 7,955 & $7,82 \mathrm{I}$ & $8,0 \mathrm{II}$ & 7,837 \\
With disability & $43 \mathrm{I}$ & 474 & 539 & 557 & 607 \\
(applicants) & $(2.9 \%)$ & $(2.7 \%)$ & $(2.8 \%)$ & $(2.9 \%)$ & $(3.3 \%)$ \\
With disability & 212 & 196 & 201 & 223 & $24 \mathrm{I}$ \\
(accepted) & $(2.8 \%)$ & $(2.5 \%)$ & $(2.6 \%)$ & $(2.8 \%)$ & $(3.1 \%)$ \\
With LDs & 191 & 194 & 249 & 296 & 324 \\
(applicants) & $(1.3 \%)$ & $(1.1 \%)$ & $(1.3 \%)$ & $(1.6 \%)$ & $(1.7 \%)$ \\
With LDs & 101 & 98 & 95 & 136 & 147 \\
(accepted) & $(1.3 \%)$ & $(1.2 \%)$ & $(1.2 \%)$ & $(1.7 \%)$ & $(1.9 \%)$ \\
LD applicants & $47.6 \%$ & $50 \%$ & $47.3 \%$ & $61 \%$ & $61 \%$ \\
(accepted) as \% of & & & & & \\
total applicants with & & & & & \\
disability (accepted) & & & & & \\
\hline Note: Daw wer
\end{tabular}

Note: aData were received through Universities and Colleges Admissions Service. Statistical services: Applicant and accepted applicant disability data over five years (2003-2007) in medical schools in the UK. these should be supported by adequate policies, provisions, and practices to make the learning meaningful and socioculturally relevant. ${ }^{46}$ Recent years have seen initiatives in many countries that aimed at broadening access to undergraduate medical education, ${ }^{3,4}$ and, as a result, students from different social and ethnic backgrounds, including those with LDs, are now attending medical schools and experiencing high-quality academic provision and social life.

As with other HE institutes, increasing number of students with a wide range of disabilities are applying to medical school year after year., 73 "LD students in medical schools are highly motivated to become physicians. They work hard, rarely give up, and experience considerable hardships in their quest. They devote more time to studying than do non-LD students". ${ }^{8}$ These groups of students experience and encounter a number of psychological difficulties, including stress and anxiety, more often than do their non-LD peers. Students with LDs find that their academic studies demand more time, greater effort, constant self-regulation, adjustment to change, a greater need for dealing with criticism, and a greater adjustment to university life. ${ }^{47,48}$

Many bright students with LDs are typically unaware of their disorder and learn to compensate effectively for their weaknesses. ${ }^{9}$ They may only learn of these when their compensatory abilities fail to cope with the demands of teaching using their previously developed compensatory study techniques. ${ }^{49}$ Students with LDs usually receive lower test scores and grades ${ }^{50-52}$ which cause persistent feelings of lower self-efficacy and lower perceptions of their academic and intellectual abilities. ${ }^{51,52}$ A study using a database of all students in HE in the United Kingdom in 1995-1996 reported that students with LDs are more likely to withdraw during their first year of study and were less likely to complete their programs of study. ${ }^{10}$ The study also noted that those who completed first-degree programs tended to gain a poorer class of honors than did non-LD students. LDs also have a negative effect on students' professional practice and career progression. ${ }^{11-13}$ Considering all this evidence, it is possible that an underperforming medical student/physician may have an undiagnosed LD that requires professional intervention. ${ }^{53}$

Research into LDs in HE, including medical education, is almost nonexistent in developing countries, especially in Asia. LDs is seen as a "disability of children" and, moreover, misconceptions ${ }^{54}$ and reservations about LDs among students, ${ }^{55-57}$ teachers, ${ }^{6,57}$ administrators, and policymakers ${ }^{57,58}$ discourage policy formulation and prevent students gaining access to the support and provisions that are needed. 
Table 5 Students with LDs are in medicine, nursing, dental, and pharmacy

\section{Medicine}

- A survey conducted in 93 medical schools in the United States and Canada reported that the incidence of LDs among medical students had more than doubled, from a mean of I.34 per school in 1988-1990 to 2.90 per school in 1993-1994, ranging from 0-16 students per school.11

- A 7-year retrospective study of Marshall University Medical HELP program, West Virginia, USA demonstrated that out of 86 students and physicians, $2 \mathrm{I}$ had LDs, $2 \mathrm{I}$ had a potential visual/spatial learning problem, 10 subjects had ADHD, and I5 subjects had both reading disability and $\mathrm{ADHD}{ }^{42}$

- At the Albert Einstein College of Medicine (USA), I\%-2\% of students in each class were referred for evaluation for LDs. ${ }^{9}$

- Leinster and Gibson ${ }^{43}$ reported a high proportion of dyslexic students at East Anglia Medical School (UK), ranging from 7\%-14\% between cohorts, up to 10 times the national average.

\section{Dentistry}

- A study conducted in US dental schools found that the mean prevalence of identified diagnosed cases of LDs from 1995 to 200 I was $0.7 \%$, and that the mean cumulative incidence during this period was $0.3 \%{ }^{38}$

\section{Nursing}

- A survey in the United States revealed that $45 \%$ of nursing programs admitted new students having disabilities, with dyslexia being the most prevalent disability. ${ }^{32}$

Pharmacy

- In UK pharmacy students, dyslexia sufferers constituted up to $21 \%$ of the disabled group but constituted less than $1 \%$ of the total student population. ${ }^{40}$

Notes: ADHD is one of the most common childhood disorders and can continue through adolescence and adulthood. Symptoms include difficulty in staying focused and paying attention, difficulty in controlling behavior, and hyperactivity (over activity).

Abbreviations: ADHD, attention deficit hyperactivity disorder; LDs, learning disabilities.

As mentioned earlier, the authors searched the databases, books, journals, and contacted relevant organizations and persons; however, no significant data were retrieved for LDs in relation to Asian countries. HE institutions, including medical schools, in Asia should be aware of LDs and their consequences on students' learning, and appropriate policies should be developed to widen the access of disadvantaged and underprivileged sections of people.

\section{Screening and diagnosis of LDs in medical students}

"Asians with dyslexia are more likely to go undiagnosed". ${ }^{59}$

The assessment of medical students, or of any adult with LDs, differs significantly from the diagnosis of children. ${ }^{8,38} \mathrm{~A}$ comprehensive assessment plan for diagnosis is required to outline an appropriate intervention program ${ }^{60}$ (Table 6). Minimally, the domains to be addressed in screening and diagnosis of LDs must include aptitude/cognitive, academic achievement, and information-processing abilities. ${ }^{8}$ In the developed countries, HE institutes, including medical schools, use annual screening exercise and educational psychologist assessments for all new students within the first few weeks of the academic year in an induction or introductory lecture to identify the presence of LDs. ${ }^{21}$

\section{Policies, provision, and practice to support LDs}

"Interviews with students with LDs showed that they do not often receive support services, their "stories" are not believed, and they often feel that they do not "belong.", ${ }^{14}$
The provision of educational support for students with LDs is well established in HE in developed countries. . $^{37,61}$ Studies showed that the impact of LDs without support and services is enormous. ${ }^{21}$ There are laws in place in many countries to prevent discrimination against qualified students and applicants with LDs. Medical schools in Asia should develop policies, provisions, and practices to support students with LDs in medical education (Table 7).

\section{National and institutional policies}

Legal enforcement and formal recognition of disability have important implications for medical education ${ }^{62}$ - health care/ professional organizations should develop initiatives to raise awareness of LD issues. ${ }^{63,64}$ Faigel $^{65}$ reported improved services in US and Canadian medical schools after the implementation of the American Disability Act of 1991. Medical schools should develop policies and procedures in strategic planning and resource allocation to support the academic and social lives of students with LDs. Asian countries should have their own national disability policy approved at the highest political level and communicated to all parties involved.

Table 6 Comprehensive assessment plan for diagnosis of LDs ${ }^{60}$

Five steps:

I. Initial interview

2. Tests of cognitive functioning and information processing

3. Tests of academic achievement levels

4. Social and emotional evaluations

5. Feedback interview 
Table 7 LD policies, provisions, and practices in 3 principle areas

\section{Policies}

- Formulation of national and institutional policies to

Meet the needs of students with LDs

Train medical students on LD issues

Train, recruit, and retain health care professionals with LDs

Create an LD-friendly workplace environment

- Medical schools should ensure that all their programs, services,

activities, and resources are supportive to students with LDs

- Equal opportunity for admission - students cannot be treated differently because of their disability, ie, denied admission or enrolment, graded poorly, failed, suspended, expelled, or harassed

Resources

- Free screening and assessment of LDs

- Reasonable accommodations for qualified students with LDs

- Guidance and awareness information (eg, web based) for students, teachers, and other staff

- Funding to run academic and training programs, to support students and to conduct research and staff development programs

- LD-friendly assessment strategies which do not use language and memorization as major contributing factors

Training

- Medical schools should have staff trained to identify students with LDs

- All staff should be trained in the awareness and understanding of LDs and in how to provide accommodations within a normal teaching/ learning situation

- Medical schools should run programs to increase students' awareness of LDs

Abbreviation: LD, learning disability.

Medical students ${ }^{66,67}$ and health care/professional organizations ${ }^{57,58,63,64,68,69}$ have a vital role in developing awareness and formulating policies and guidelines. Physicians with disabilities have been at the forefront of legislative and organizational reform to bring improved admission rates of disabled students and increase the retention of disabled physicians in the profession. ${ }^{70}$ Legal actions have been undertaken by medical students with LDs to establish their rights for admission and accommodation. ${ }^{66,67}$ Professionals other than health care professionals can also play an important role in bringing awareness. For example, the recent, commercially successful Hindi movie Taare Zameen Par (Stars on the Earth), which sensitively and accurately portrayed the plight of an 8-year-old boy battling LDs, helped to raise awareness in the community. ${ }^{16}$

\section{Admission to medical education}

In selecting students, medical schools should ensure equitable consideration of all applicants. ${ }^{41}$ Admission policies should be made available to prospective students, especially in electronic form, eg, the use of Web sites. Medical schools may not enquire whether an applicant has LDs. An applicant with LDs can request for an admission test in an alternative form if a standard test appears inappropriate and discriminatory. ${ }^{71}$ Applicants should be generally encouraged to inform schools about their disabilities if they require any accommodations. ${ }^{72}$ Medical schools should consider providing disability awareness/equality guidance and training for all tutors and administrative staff involved in the admission process. ${ }^{73}$ The Council of Heads of Medical Schools (United Kingdom) published "Best Practice Guidelines" for the selection of LD students by medical schools to confirm that "someone has reached the requisite academic level but that they are also fit to practice medicine, which is not simply a question of academic attainment". ${ }^{74}$

\section{Accommodating medical students with LDs}

"The basic goal of the accommodation is to afford an individual with a disability an equal opportunity to participate in, and enjoy the benefits of (the higher education program) ". ${ }^{71}$

Reasonable accommodations (Table 8) mean adjustments or modifications made to an institute policy, or specific support or services provided to disabled students, to enable students to participate adequately in educational programs. ${ }^{37,75}$ Typically, students with LDs receive accommodations appropriate to their disability in order to "level the playing field". ${ }^{76}$ During examinations, students with LDs usually experience stress, nervousness, frustration, helplessness, or are uncertain during examinations than students without LDs as they have difficulty in concentrating and are concerned about lack of time. ${ }^{77}$ Appropriate accommodations should be granted both in undergraduate and postgraduate admissions and in licensure examinations. The 1994 survey of LDs in US medical schools reported the use of a large array of approaches for accommodating students with LDs, eg, extra time for exams ( $89.2 \%$ of responding schools), audiotaping or videotaping of classes $(60.2 \%)$, special tutoring (73.1\%), and close monitoring of progress $(79.6 \%) .{ }^{41}$ The most frequent accommodation used is the provision of extra time in a written exam in a separate room.

Accommodations help to increase the academic performance of students with LDs. ${ }^{9,10}$ However, sometimes teachers and administrators suspect that some students with LDs diagnoses "might be faking a disability to gain an educational advantage". ${ }^{6}$ Another area of concern is whether all these accommodations give students with LDs an unfair advantage over non-LD students. It was demonstrated that extra time helped students with LDs to increase their performance but did not significantly change the scores of their non-LD peers. ${ }^{78}$ 
Table 8 Reasonable accommodations ${ }^{6}$

\begin{tabular}{|c|c|}
\hline Academic adjustments & Auxiliary aid and services \\
\hline $\begin{array}{l}\text { Academic adjustments are modifications to academic program to accommodate } \\
\text { the needs of a student with a disability. } \\
\text { - Extra time for examinations (usually an additional } 25 \% \text { in written examinations) } \\
\text { - Not assessing penalties for spelling errors on papers or exams } \\
\text { - Allowing substitutions for certain required or prerequisite courses } \\
\text { - Copies of lecture notes and handouts prior to lectures } \\
\text { - Extended library loans } \\
\text { - Providing examinations in alternative formats, such as oral instead of written } \\
\text { - Allowing a reduced course load } \\
\text { - Lengthening the time for degree completion }\end{array}$ & $\begin{array}{l}\text { Auxiliary aid/services to meet the needs of students with } \\
\text { disabilities who have impaired sensory, manual, or speaking } \\
\text { skills or other requirements. } \\
\text { - Interpreters } \\
\text { - Note-taker/reader/scribe } \\
\text { - Audio-taping or video-taping of classes } \\
\text { - Video-text displays } \\
\text { - Braille calculators, printers, or keyboards } \\
\text { - Listening devices or systems } \\
\text { - Academic, personal, and vocational counseling } \\
\text { - Materials provided in alternative media such as large print } \\
\text { - Support in searching for books/journals in libraries }\end{array}$ \\
\hline
\end{tabular}

\section{Funding}

As most medical schools in Asia usually struggle with funding, the allocation of extra funds to another "unproductive area" is often difficult. ${ }^{45}$ Funding is a major hurdle for HE institutes in giving support to students with LDs. ${ }^{79}$ The 1994 survey in US medical schools reported that the cost of the evaluation of LDs was paid entirely by the school in $27.4 \%$ of respondent schools, entirely by students in $34.4 \%$ of schools, and by a combination of both in $40.9 \%$ of schools. ${ }^{41}$ The report also noted that $38.75 \%$ of schools paid the entire cost of accommodation provided. Medical schools in Asia can look for external funding (eg, ministry of health, ministry of education, and WHO), and in that case, students need not be charged for the support and services needed. Funding is also needed to organize staff development programs for teachers/staff and to conduct research on LD issues.

\section{Staff development and awareness}

Studies showed that most teachers in HE are neither aware of LD issues nor trained to aid students with LDs; ${ }^{80}$ this is predominant in Asian countries. Medical schools should organize "universal disability-awareness training" ${ }^{57}$ for their staff and provide useful Web-based information to make teaching/learning practices more inclusive of students with LDs. Medical schools need to ensure that there are trained staff to provide specialist advice and support for LD applicants/students and staff. Seminars, conferences, and workshops on LDs can be organized to increase the awareness and knowledge of health professionals, including medical teachers. Research councils and other organizations should have specific programs and funds to conduct research on LDs, and evidence-based policies should be developed to provide support for students with LDs.

\section{Training of tomorrow's doctors}

The LD population in the community is increasing. However, physicians' lack of experience in caring for this population is documented in many research papers. ${ }^{81,82} \mathrm{~A}$ WHO report noted the lack of general training in LDs among primary health care providers and recommended appropriate needbased training for them. ${ }^{81}$ Moreover, poor attitudes among health care workers can contribute significantly to people with disabilities feeling isolated, disempowered, and disengaged with health care services. ${ }^{82}$

The teaching of disability and rehabilitation, even in the medical schools of developed countries, is "patchy, sporadic, and rarely had clearly defined aims and objectives, ${ }^{, 83}$ and the scenario in Asian medical schools is far from being the worst. The need for advanced knowledge and skills among medical students to serve people with LDs adequately has been widely recognized, ${ }^{84}$ and it was emphasized that more attention should be paid to train students. ${ }^{55,56,85}$ The provision of positive experiences (eg, electives) causes significant shifts in students' attitudes toward people with LDs. ${ }^{83,86}$ Medical schools need to define core curriculum, teaching/learning strategies, and evaluation techniques so that students can deal effectively with LDs later in their professional practice ${ }^{87,88}$ Appropriate training and experience will motivate doctors to take on a public health role to improve the health and well-being of people with LDs, prevent disease and minimize its consequences, adopt healthpromotion strategies, and reduce inequalities in health. ${ }^{57,69}$

\section{Working practices and career progression in health professionals with LDs}

Health professionals with LDs live under the constant pressure of satisfying expectations from a variety of sources, 
particularly relating to gaining and retaining employment. ${ }^{5}$ As a hidden disability, LDs have the potential to be "misunderstood and misjudged" within the medical profession, ${ }^{13}$ and fears for the safety of patients being cared by health professionals have been raised. ${ }^{57,69}$ The reasons for nondisclosure, or selective disclosure, of LDs among health professionals is another issue that needs appropriate attention; the causes of which include the fear of ridicule, of blame, and of victimization; worries about job security and discrimination; and the belief that there is a lack of understanding in the profession. ${ }^{12,57,68,69} \mathrm{This}$ issue is more commonly noticed in "culturally and religiously conservative" societies in Asian countries. ${ }^{46}$ The General Medical Council (United Kingdom) ${ }^{37}$ outlined "academic or other prescribed standards" and "fitness to practice rules," and the British Medical Association ${ }^{57,69}$ and Department of Health (United Kingdom) ${ }^{64}$ published disability equality guidelines to attract and retain people with disability in the profession. The General Medical Council (GMC) policy statement for "fitness to practice" states that "doctors must not allow their own health condition to endanger patients" and take responsibility for their health in the interests of patient safety. ${ }^{57}$ Asian countries should take initiatives to develop such guidelines to train, recruit, and retain health care professionals and to create an LD-friendly, inclusive working environment.

\section{Physicians/scientists celebrities with LDs}

"Dyslexia didn't stop these famous men and women from achieving greatness. In some cases it may have fueled their creative fires". ${ }^{89}$

Another legitimate question is whether students with LDs can cope with the demands of health care courses and clinical practices. There is no strong evidence to suggest that people with LDs cannot cope with studying, or with becoming a qualified health professional. However, it is encouraging to know that, within the field of medicine/science, a number of celebrated physicians/scientists with LDs have done great things (Table 9). ${ }^{8,57,72}$

\section{Conclusion}

Medicine is a field that requires a focused learning style and approach. ${ }^{72}$ Studying medicine can be more stressful if strategies for coping with LDs are not effectively adapted to meet the demands and needs related to the course. It is of utmost importance to detect and support students with LDs early, enabling them to maximize their potential. Medical schools in Asia must determine how a qualified applicant with LDs can be effectively accommodated and counseled, taking into consideration local resources, facilities, values, and customs. Appropriate policies and programs need to be developed to promote medicine as a potential career for people with disabilities, in partnership with other professional organizations. Further research is required to determine the LDs prevalence/incidence in health professional education in Asia and to identify the nature and extent of support that is currently available and required. Similar initiatives should be taken in HE to develop policies and institutional commitment, which will allow students, faculties, and administrations to work together toward a common goal "successful education for students with LDs".

\section{Acknowledgments}

The authors are very grateful to the Universities and colleges Admissions Service (UCAS), UK for providing the disability data for medical schools in the UK (Table 4). The authors also wish to thank all the reviewers for their constructive comments.

\section{Disclosure}

The authors report no conflicts of interest in this work.

Table 9 Celebrated physicians/scientists with LD $8,57,72$

\begin{tabular}{lll}
\hline Physicians/scientists & Contribution & Learning disability \\
\hline $\begin{array}{l}\text { John Hunter (I728-1793) } \\
\text { Arthur Conan Doyle (1859-1930) }\end{array}$ & $\begin{array}{l}\text { Founder of scientific surgery } \\
\text { Creator of detective hero Sherlock Holmes }\end{array}$ & Dyslexia \\
Dyscalculia \\
Harvey Cushing (I869-1939) & $\begin{array}{l}\text { Founder of analytical psychology } \\
\text { Pioneer of brain surgery }\end{array}$ & $\begin{array}{l}\text { Dyscalculia } \\
\text { Developmental disorder } \\
\text { of language }\end{array}$ \\
Paul Ehrlich (I854-1915) & Discovered the first effective treatment for syphilis and & Developmental disorder of written \\
& won the I908 Nobel Prize in physiology or medicine & language \\
Albert Einstein (1879-1955) & Authored special and general theories of relativity & Dyslexia \\
Alexander Graham Bell (1847-1922) & Inventor of telephone & Dyslexia \\
Thomas Edison (I847-193I) & Inventor of light bulb & Dyslexia \\
Isaac Newton (1643-1727) & Described universal gravitation and 3 laws of motion & Dyslexia \\
Louis Pasteur (1822-1895) & Discovered pasteurization and created the first vaccine for rabies & Dyslexia \\
\hline
\end{tabular}




\section{References}

1. Universities UK. Fair Enough: Wider Access to University by Identifying Potential to Succeed. London, UK: Universities UK; 2003.

2. Universities Australia. Advancing Equity and Participation in Australian Higher Education: Action to address participation and equity levels in higher education of people from low socioeconomic backgrounds and Indigenous people. Canberra, Australia: Universities Australia; 2008.

3. Beedham C, Diston A, Cottrell D, Drew C. Widening participation in medicine: the Bradford Leeds Partnership. Clin Teach. 2006;3: $158-162$.

4. Jamieson C, Morgan E. Managing Dyslexia at University. A Resource for Students, Academic and Support Staff. London, UK: Routledge; 2008.

5. Reid G, Kirk J. Dyslexia in Adults: Education and Employment. Chichester, UK: John Wiley and Sons, Ltd; 2001.

6. Wolanin TR, Steele PE. Higher Education Opportunities for Students with Disabilities: Primer for Policy Makers. Washington, DC: The Institute for Higher Education Policy; 2004.

7. Universities and Colleges Admissions Service. Statistical services: Breakdown of applicant and accepted applicant disability data over six years. Available from: http://www.ucas.com/about_us/stat_services/ stats_online/data_tables/disability. Accessed Jun 25, 2010.

8. Rosebraugh CJ. Learning disabilities and medical schools. Med Educ. 2000;34:994-1000.

9. Walters JA, Croen LG. An approach to meeting the needs of medical students with learning disabilities. Teach Learn Med. 1993;5:29-35.

10. Richardson JTE, Wydell TN. The representation and attainment of students with dyslexia in UK higher education. Read Writ. 2003;16: 475-503.

11. Illingworth $\mathrm{K}$. The effects of dyslexia on the work of nurses and healthcare assistants. Nurs Stand. 2005;19:41-48.

12. Morris D, Turnbull P. Exploring the clinical experiences of preregistration student nurses with dyslexia. J Adv Nurs. 2006;54: 238-247.

13. Morris D, Turnbull P. A survey-based exploration of the impact of dyslexia on career progression of UK registered nurses. J Nurs Manage. 2007;15:97-106.

14. Ryan J. Learning Disabilities in Australian Universities: hidden, ignored, and unwelcome. J Learn Disabil. 2007;40:436-442.

15. Smythe I, Everatt J, Salter R. International Book of Dyslexia: A Guide to Practice and Resources. Chichester, UK: John Wiley and Sons, Ltd; 2004.

16. Karande S, Mehta V, Kulkarni M. Impact of an education program on parental knowledge of specific learning disability. Indian J Med Sci. 2007;61:398-406

17. Elbeheri G. Brief report on the achievements of the Early Learning Challenges Project (2nd CCF/2002-2007). Available from: http:// www.undpkuwait.org/undpkuw/showcasing/Early\%20Learning\%20 Challenges\%20Programme\%20Dr.\%20Gad\%20Al\%20Behairi.pdf. Accessed Jun 25, 2010.

18. Silver LB. The Misunderstood Child: A Guide for Parents of Children with Learning Disabilities. 3rd ed. New York, NY: Times Books; 1998.

19. McLean P, Bruce G, Powell J. Learning Disabilities in Higher Education. Melbourne, Australia: University of Melbourne and Monash University; 1995.

20. Interagency Committee on Learning Disabilities. Learning Disabilities: A Report to the US Congress. Bethesda, MD: National Institutes of Health; 1987.

21. University of Bradford. 3D support: Support for students with dyslexia, dyspraxia, and dyscalculia. Available from: http:/www.brad.ac.uk/ $\mathrm{admin} /$ disab/3dsupport/3dsupport.pdf. Accessed Jun 25, 2010.

22. Learning Disabilities Association of Western New York. What are learning disabilities? Available from: http://www.ldaofwny.org/what_are_lds. htm. Accessed Jun 25, 2010.

23. Spaeth A. Minds at risk. Time Magazine. Jul 28, 2003.
24. The European Dyslexia Association. Strengths and weaknesses. Available from: http://www.dyslexia.eu.com/strengths.html. Accessed Jun 25, 2010.

25. The Parliamentary Office of Science and Technology. Dyslexia and Dyscalculia. Post note, Number 226. London, UK: The Parliamentary Office of Science and Technology; 2004.

26. International Dyslexic Association. Dyslexia Basics. Available from: http://www.interdys.org/ewebeditpro5/upload/Basics_Fact_Sheet_508-08.pdf. Accessed Jun 25, 2010.

27. Smythe I ed. Provision and Use of Information Technology with Dyslexic Students in University in Europe. Available from: http://eprints. ecs.soton.ac.uk/14151/1/The_Book.pdf. Accessed Jun 25, 2010.

28. Ministry of Education, Kingdom of Saudi Arabia. Conference to Counter Learning Disabilities. Available from: http://www.moe.gov.sa/ openshare/englishcon/Conference-to-Counter-Learning.htm_cvt.html. Accessed Jun 25, 2010.

29. Chan CW. Overview of specific learning disabilities (SLD)/dyslexia developments over the last decade in Hong Kong. HK J Paediatr. 2008; 13:196-202.

30. API INFO NET. Learning disorders in APIA adolescents. Available from: http://www.sph.umich.edu/apihealth/Mental\%20health $\% 20$ learning.html. Accessed Jun 25, 2010.

31. Lewin T. For learning disabled, New Help with College. New York Times. Posted on Jan 8, 1995: Available from: http://www.nytimes. com/1995/01/08/education/for-learning-disabled-new-help-withcollege.html?sec=health. Accessed Jun 25, 2010.

32. Watson P. Nursing students with disabilities: a survey of baccalaureate nursing programs. J Prof Nurs. 1995;11:147-153.

33. Singleton CH. Dyslexia in Higher Education: Policy, Provisions, and Practice. Report of National Working Party on Dyslexia in Higher Education. Hull, UK: University of Hull; 1999.

34. Stampoltzis A, Polychronopoulou S. Dyslexia in Greek higher education: a study of incidence, policy, and provision. J Res Spec Educ Needs. 2008;8:37-46.

35. Moore-West M, Heath D. The physically handicapped student in medical school: a preliminary study. J Med Educ. 1982;57:918-921.

36. Wu SSH, Tsang P, Wainapel SF. Physical disability among American medical students. Am J Phys Med Rehab. 1996;75:183-187.

37. General Medical Council. Gateways to the Professions. Advising Medical Schools: Encouraging Disabled Students. London, UK: General Medical Council; 2008.

38. Cruikshank D, Howell TH, Brinckerhoff LC, Badovinac R, Karimbux NY. Learning disabilities in dental education: trends, management, and concerns in US dental schools. J Dent Educ. 2002;66:1178-1184.

39. Parks AW, Antonoff SJ, Drake C, et al. Screening for specific learning disabilities among dental students. J Dent Educ. 1982;46:586-591.

40. Hartley J. What are UK schools of pharmacy providing for undergraduates with disabilities? Pharm J. 2006;276:444-446.

41. HEATH Resource Center. College Freshmen with Disabilities. Washington, DC, USA: Heath Resource Center; 1995.

42. Banks SK, Guyer B, Guyer K. A study of medical students and physicians referred for learning disabilities. Ann Dyslexia. 1995;45:233-245.

43. Leinster SL, Gibson S. Dyslexia; a real or perceived problem in medical assessments. Poster presented at: Ottowa, 2008.

44. Majumder MAA, D'Souza U, Rahma S. Trends in Medical Education: challenges and directions for need-based reforms of medical training in south-east Asia. Indian J Med Sci. 2004;58:369-380.

45. Majumder MAA. Issues and priorities of medical education research in Asia. Ann Acad Med Singapore. 2004;33:257-263.

46. Majumder MAA. Development of a Culturally Relevant Operational Model for Evaluation of the Undergraduate Curriculum in the Medical Colleges of Bangladesh. [thesis]. Dundee, UK: University of Dundee; 2000.

47. Barton RS, Fuhrman BS. Counseling and psychotherapy for adults with learning disabilities. In: Gerber PJ, Reiff HB, editors. Learning Disabilities in Adulthood: Persisting Problems and Evolving Issues. Austin, TX: PRO-ED;1994:82-92. 
48. Saracoglu B, Minden H, Wilchesky M. The adjustment of students with learning disabilities to university and its relationship to self-esteem and self-efficacy. J Learn Disabil. 1989;22:590-592.

49. Takakuwa KM. Coping with a learning disability in medical school. JAMA. 1998;279:81.

50. Rochford K. Spatial learning disabilities and underachievement among university anatomy students. Med Educ. 1985;19:13-26.

51. Hoy C, Gregg N, Wisenbaker J, Manglitz E, King M, Moreland C. Depression and anxiety in two groups of adults with learning disabilities. Learn Disability Quart. 1997;20:280-291.

52. Murray C, Goldstein DE, Nourse S, Edgar E. The postsecondary school attendance and completion rates of high school graduates with learning disabilities. Learn Disabil Res Pract. 2000;15:119-127.

53. Johnson AD. A review of exam accommodations for dental students with disabilities. J Dent Educ. 2006;70:475-479.

54. Yom SS. Disabilities: looking back and looking ahead. JAMA. 1998; 279:78.

55. Tervo RC, Azuma S, Palmer G, Redinius P. Medical students' attitudes toward persons with disability: a comparative study. Arch Phys Med Rehab. 2002;83:1537-1542.

56. Tervo RC, Palmer G. Health professional student attitudes towards people with disability. Clin Rehabil. 2004;18;908-915.

57. BMA Equal Opportunities Committee. Disability Equality in the Medical Profession. London, UK: British Medical Association; 2007.

58. Little D. Learning disabilities, medical students, and common sense. Acad Med. 1999;74:622-623.

59. Gorman C. The New Science of Dyslexia. Time Magazine. Jul 28, 2003.

60. The Learning Disabilities Association of Ontario. The Adult with Learning Disabilities and Assessment. Available from: http://www.ldao.ca/ uploads/news_files/News_57_Adults\%20with\%20LD\%20and\%20 Assessment.pdf. Accessed Jun 25, 2010.

61. Chalkley B, Waterfield J. Providing learning support for students with hidden disabilities and dyslexia undertaking fieldwork and related activities. Cheltenham, UK: Geography Discipline Network (GDN); 2001.

62. Essex-Sorlie D. The Americans with Disabilities Act II: implications and suggestions for compliance for medical schools. Acad Med. 1994;69:525-535.

63. AAMC. The Americans with Disabilities Act (ADA), and the Disabled Student in Medical School: Guidelines for Medical Schools. Washington, DC, USA: Association of American Medical Colleges; 1993.

64. Department of Health. Looking Beyond Labels: Widening the Employment Opportunities for Disabled People in the New NHS. London, UK: Department of Health; 2001.

65. Faigel HC. Changes in services for students with learning disabilities in US and Canadian medical schools, 1991-1997. Acad Med. 1998;73:1290-1293.

66. Lipsett A. Dyslexic student fights exam system. Available from: http:// www.guardian.co.uk/education/2008/jul/29/dyslexia.exams. Published Jul 29, 2008. Accessed Jun 25, 2010.

67. Hafferty FW, Gibson GG. Learning disabilities, professionalism, and the practice of medical education. Acad Med. 2003;78:189-201.

68. British Medical Association. Career Barriers in Medicine: Doctor's Experiences. London, UK: British Medical Association; 2004.

69. BMA Equal Opportunities Committee and Patient Liaison Group. Disability Equality Within Healthcare: The Role of Healthcare Professionals. London, UK: British Medical Association; 2007.
70. Association of Academic Physiatrists. Recommended Guidelines for Admission to Medical School of Candidates with Disabilities. Indianapolis, IN: Association of Academic Physiatrists; 1995.

71. Office for Civil Rights. US Department of Education. Students with Disabilities Preparing for Postsecondary Education: Know Your Rights and Responsibilities. Washington, DC, USA: US Department of Education; 2002.

72. British Medical Association. Studying medicine with dyslexia: Best practice guidance from the BMA medical students committee (MSC) (May 2006). Available from: http://www.bma.org.uk/ap.nsf/Content/ dyslexia. Accessed Jun 25, 2010.

73. Quality Assurance Agency for Higher Education. Codes of Practice for the Assurance of Academic Quality and Standards in Higher Education. Gloucester, UK: Quality Assurance Agency for Higher Education; 1999.

74. Council of Heads of Medical Schools. Recommendations on Selection of Medical Students with Specific Learning Disabilities including Dyslexia. Available from: http://www.medschools.ac.uk/AboutUs/ Projects/Documents/Recommendations\%20on\%20Selection\%20 of $\% 20$ Students $\% 20$ with $\% 20$ specific $\% 20$ learning $\% 20$ disabilities, $\% 20$ including\%20dyslexia.pdf. Accessed Jun 25, 2010.

75. Watson JE, Hutchens SH. Medical Students with Disabilities: A Generation of Practice. Washington, DC: Association of American Medical Colleges; 2005.

76. Scott SS. Determining reasonable academic adjustments for college students with learning disabilities. J Learn Disabil. 1994;27:403.

77. Heiman T, Precel K. Students with learning disabilities in higher education: students with learning disabilities in higher education: academic strategies profile. J Learn Disabil. 2003;36;248-258.

78. Runyan KM. The effect of extra time on reading comprehension for LD and non-LD university students. J Learn Disabil. 1991;24:104-108.

79. Wright DJ. Educational support for nursing and midwifery students with dyslexia. Nurs Stand. 2000;14:35-41.

80. Nganasurian W. Spelling it out. Nurs Stand. 1994;8:42-43.

81. Janicki MP, Breitenbach N. Aging and Intellectual Disabilities: Improving longevity and promoting healthy aging. Summative report 2000. Geneva, Switzerland: World Health Organization; 2000.

82. Disability Rights Commission. Discriminating Treatment? Disabled People and Health Services. DRC background paper. London, UK: Disability Rights Commission; 2004.

83. Byron M, Cockshott Z, Brownett H, et al. What does 'disability' mean for medical students? An exploration of the words medical students associate with the term 'disability'. Med Educ. 2005;39:176-183.

84. Bradley E. Preparing medical undergraduates for their increasing role with patients who also have a mental handicap: a retrospective study. Med Teach. 1988;10:283-288.

85. Burge P, Ouellette-Kuntz H, Isaacs B, Lunsky Y. Medical students' views on training in intellectual disabilities. Can Fam Physician. 2008;54(4):568-569, e1-e6.

86. Hall I, Hollins S. Changing medical students' attitudes to learning disability. Psychiatr Bull. 1996;20:429-430.

87. Piachaud J. Teaching learning disability to undergraduate medical students. Adv Psychiat Treat. 2002;8:334-341.

88. Hollins S. How mental handicap is taught in UK medical schools. Med Teach. 1988;10:289-296.

89. Dyslexia Role Models. Time Magazine. Jul 28, 2003.
Advances in Medical Education and Practice

\section{Publish your work in this journal}

Advances in Medical Education and Practice is an international, peerreviewed, open access journal that aims to present and publish research on Medical Education covering medical, dental, nursing and allied healthcare professional education. The journal covers undergraduate education, postgraduate training and continuing medical education

\section{Dovepress}

including emerging trends and innovative models linking education, research, and healthcare services. The manuscript management system is completely online and includes a very quick and fair peer-review system. Visit http://www.dovepress.com/testimonials.php to read real quotes from published authors. 